SCARA-1.05-01, (78)

\title{
Analysis and Simulation of Tandem Charge
}

\author{
Ali M. Zain*, Mohammed A. Abdalla ${ }^{\dagger}$, Nizar M. Ahamed* \\ * Sabigat Industrial Complex, Khartoum, Sudan \\ $\dagger$ University of Khartoum \\ Email: ali005039@gmail.com
}

\begin{abstract}
In the present work the PG-7 (40mm) anti tank hollow charge has been developed to double (tandem) hollow charge warhead by using simulation program. The interaction of the precursor warhead with the Explosive Reactive Armor ERA was studied and the delayed time between precursor head and the main charge was found which about $50 \mathrm{~s}$ is with $350 \mathrm{~mm}$ penetration depth. The effect of precursor charge on the main charge was also studied and this effect was isolated in the delay period, in addition to the effect of precursor warhead jetting on the rear warhead the optimum delay time was found. This study was carried out using the ANSYS AUTODYN simulation program. And the model worked in several ways to reach these goals.
\end{abstract}

Key words-Tandem, Hollow charge, ERA, AUTODYN.

\section{INTRODUCTION}

A hollow or shape charge is cylinder or semi cylinder of explosive material with a cavity in one end and a detonator device at the opposite end as shown in Fig.1.

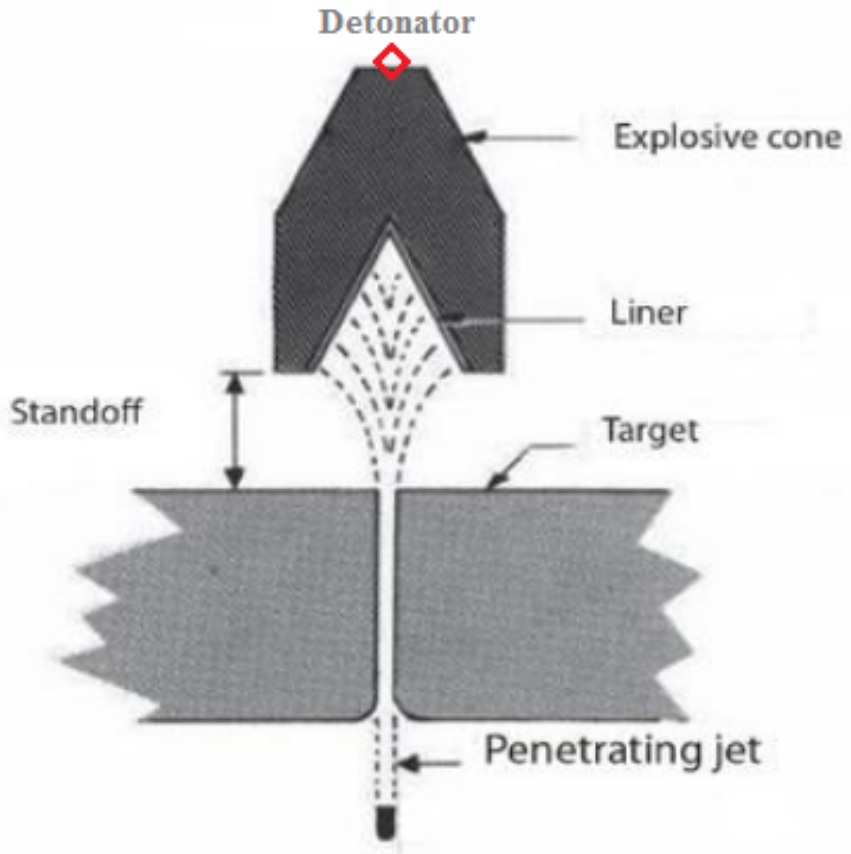

Fig. 1. The shaped charge

This hollow cavity, which can be formed at many geometric shapes such as a hemisphere, a cone, or the like, causes the gaseous products formed from explosive charge which initiated at the end of the point opposite to the hollow cavity to focus the huge energy of the explosion products and creates an intense localized force at specific point [1][2]. When the hallow charge directed against a metallic block or plate, this concentrated force is capable to creating a deeper cavity than a cylinder of explosive without a hollow cavity, even though more explosive collective available in the latter case as shown in Fig.2.

(a)

(b)

(c)

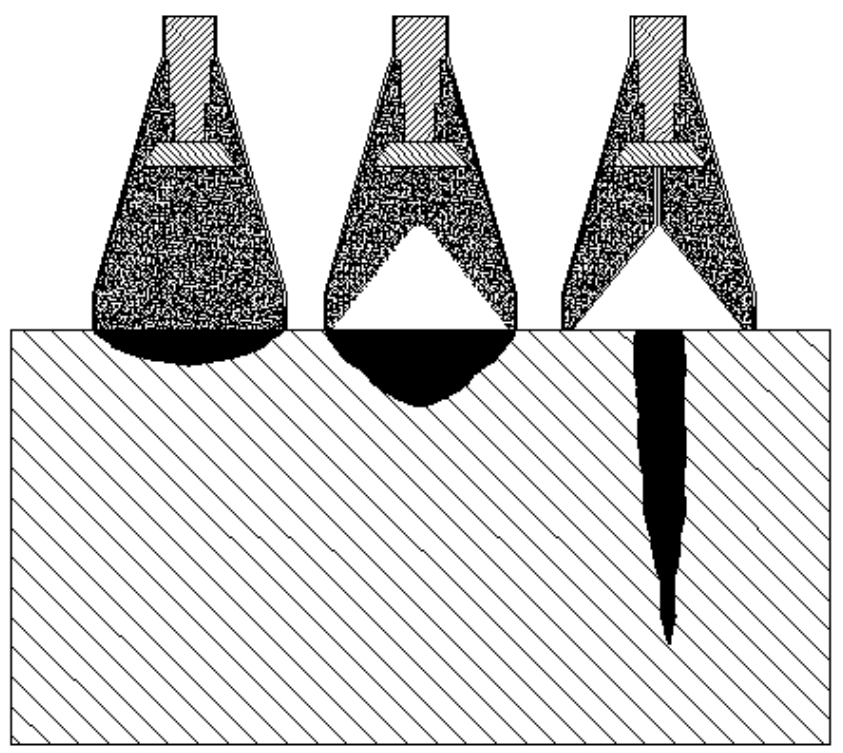

Fig. 2. Comparison between flat end and hollow cavity end

This phenomenon is defined in Europe as the Von Foerster or Neumann effect and defined in the United States and the United Kingdom as the Munroe effect and [3][4]. In any form of attack and especially for the military armors, the essential requirements are not only to penetrate, but also to have sufficient residual energy to do damage behind the plate. The main effects of the hollow charge on the targets are:

1) Penetration the armor and stopping its function by the active jet

2) Produce a strong shock wave inside internal space of the armor, which is enough to kill the crew of the armor. 
3) Some vapors of the jet liner will condense inside the internal space of the armor and forming killing fragments [4].

Tank or armor is transporting firepower in the battlefield, with its weapon system and protected crew from direct enemy fire. This modern munitions has been in existence for under a hundred years, and in that time the hollow charge has become one of the most important munitions of the battle-winning all arms team [5]. Anti Tank Warheads is a missile, rocket or gun designed to destroy or disable enemy armored vehicles. To define a hollow charge anti-tank weapons, three terms are used: "firepower kill", " mobility kill ", and "catastrophic kill" [5]. Reactive armor or Explosive Reactive Armor ERA is used to protect an armored vehicle (mostly tanks) against direct hits of conventional anti-tank weapons. Its can defeats the hollow charge jet of high explosive anti tank HEAT warheads [1][5]. Explosive Reactive Armor (ERA) is a type of armor that can reacts to the impact of an anti-tank ammunition to reduce the damage done to the vehicle being protected. ERA is most effective in protecting against hollow charges. In addition to laminate armor incorporating one or more layers of nonmetallic material, the use of hollow charge weapons also inspired the development of an additional form of protection made up of modules with a layer of an explosive sandwiched between two metal plates. This type of protection was developed in 1970s and becomes known as explosive reactive armor [6]. The multiple hits in the same point can defeat Explosive Reactive Armour, also ERA can be damage with tandem (double charges) weapons (tandem warhead).

A tandem munitions or double charge warhead is an explosive device or projectile that has two stages of detonation. This types of warhead are effective against Explosive Reactive Armor. The first charge of the initiates the reactive armor of the target, limiting the attack's effectiveness. However, after the reactive armor has protected the vehicle from the primary attack, it is no longer "reactive" in that location (since reactive armor is primarily a one-time defense solution) and the location is left more vulnerable. The second detonation from the same projectile (the rear charge) attacks the same point as the first charge where the Explosive Reactive Armor has been compromised [4]. Detonation of the forward and the second charge sequentially with a delay time $(\triangle t)$. The delay time is very important to consider to prevent the rear charge from detonating until outer or active protection has been destroyed, the delay is also necessary to prevent the rear jet from the first charge explosion. Too long delay time (t) can lead to unfavorable consequences in operation, this unsuitable delay can decrease the stand-off distance of the second warhead [4]. The conventional anti tank weapon such as (PG-7, PG-9) are not effective against modern tanks like Explosive Reactor Armor (ERA) due to their development in design and manufacturing.

In this work, the PG-7 (40mm) anti tank hollow charge has been developed to double (tandem) hollow charge warhead by using ANSYS AUTODYN simulation.

\section{MODEL DESCRIPTION}

In one particular embodiment, the forward charge has a conical metal liner whose apex angle is about 90 degrees; the average thickness of the casing is about $1.6 \%$ caliber of the war head charge, while the rear charge is PG-7 anti tank warhead. Fig. 3 shows the constriction of the tandem shape charge. As shown in Fig.3, the warhead consists of a casing 1 in which are mounted, in tandem, two shaped explosive charge 2 and 3, hereinafter referred to as the forward charge and rear charge, respectively. The forward warhead 2 includes a mass of explosives material 4 in front of which a conical metal liner 5 , and behind which is a base electrical fuse 6 . The explosive charge 4 used in the forward charge 2 must be of low-energy type, with a detonation velocity about $8000 \mathrm{~m} / \mathrm{s}$. The characteristics of the front liner 5, as well as the nature of the explosive 4 used for the forward warhead 2. The rear charge 3 , is constructed as a high-performance, high explosive hollow shaped charge, and includes an acute-angle conical liner 7, and a mass of explosive charge 8 , which is favorably a high-energy explosive, behind which is a base electrical fuse 9 connected to the front base fuse 6 by electric wire 10 and detonated by electric fuse (piezo element) 11. One particular advance of this weapons type is that it makes it possible to penetrate the explosive reactive armor with a light warhead [6].

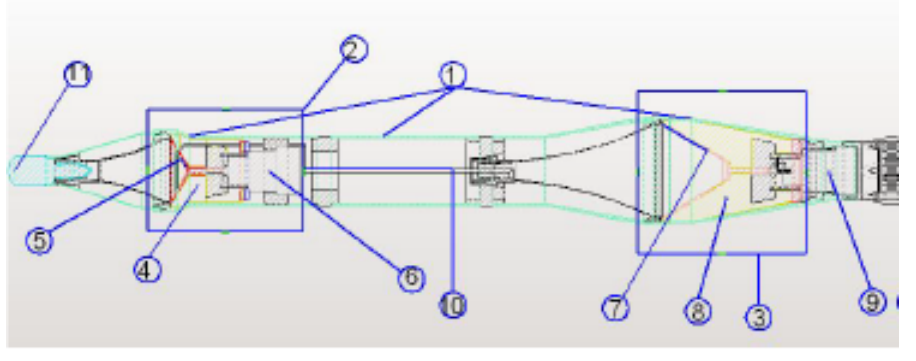

Fig. 3. . Warhead with Tandem Charge

\section{SimUlation}

This analysis of the tandem warhead targets the following points:

1) The front head interacts with the Explosive Reactive Armor ERA and then finds the delay time between the front charge and the main charge

2) Effect of front jetting on the rear and finding the final time of delay

3) The effect of the forward charge on the main charge and the isolation of this effect in the delay period

To perform this analysis, we used the ANSYS Autodyn simulation software, various models simulated to achieve these goals.

\section{A. The fully two-dimensional model}

As shown in Fig.4 it was successful in forming the jet of the front warhead. 


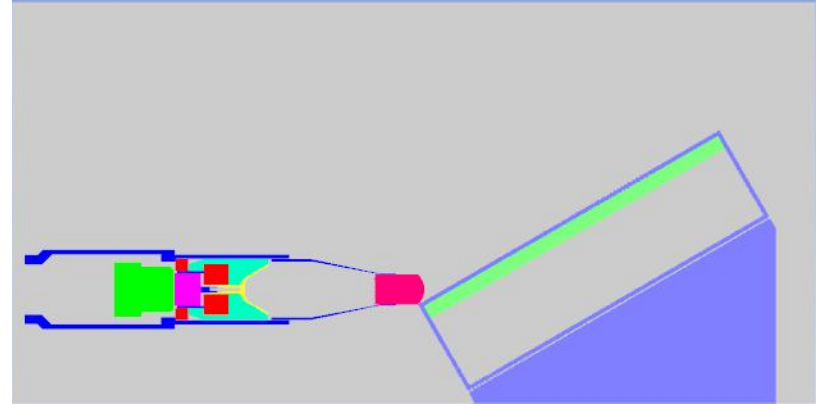

Fig. 4. Fully Two-dimensional model

\section{B. The two-dimensional with $20 \%$ from original model}

The model in III-A was scaling to become $20 \%$. This scaling may decrease accuracy but it gives a reasonable results.

\section{Three-dimensional model}

This model used to analyze the interaction between front charge jet with the explosive box as shown in Fig.5.

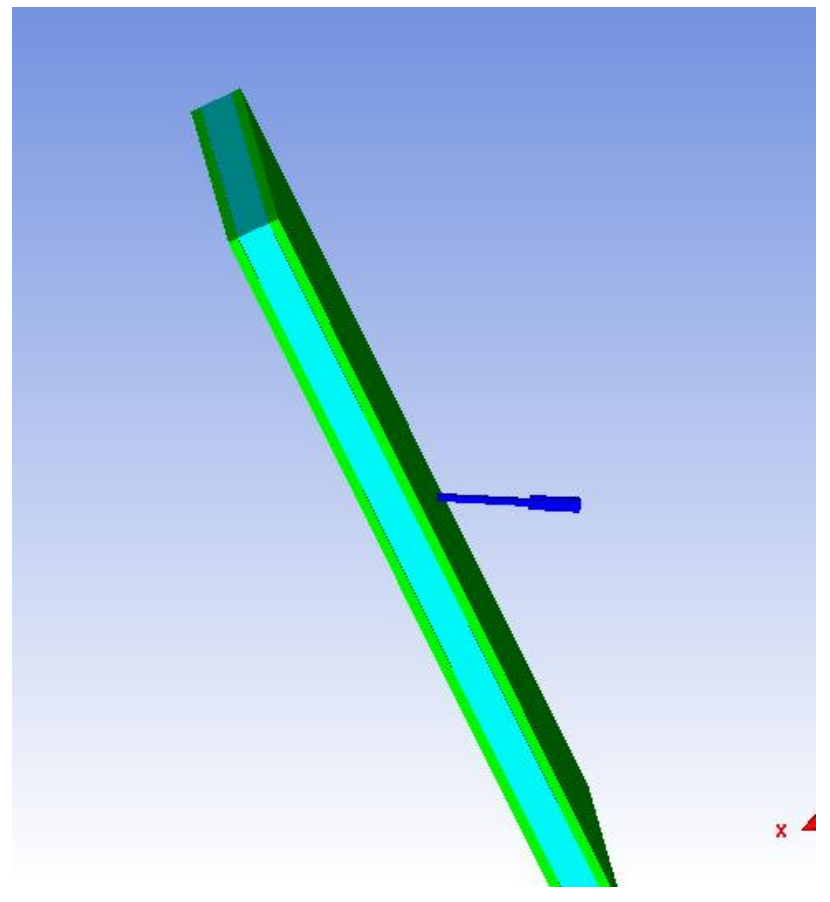

Fig. 5. 3D jet interaction

\section{ANALYSIS}

\section{A. Front Charge}

In modelIII-A by using Lagrange solver in the outer shell give good and stable results for jet formation. The threedimensional model (III-B) when we use Arbitrary Lagrange Euler (ALE) solver for explosive and setting the point at which the explosion occurs and the time of the start of this explosion led to the success of full expansion and the dispersion of the front jet occurs in a time of $27 \mathrm{~s}$ and rear jet reached to the armor at $27 \mu$ s, Fig. 6 explain this result.

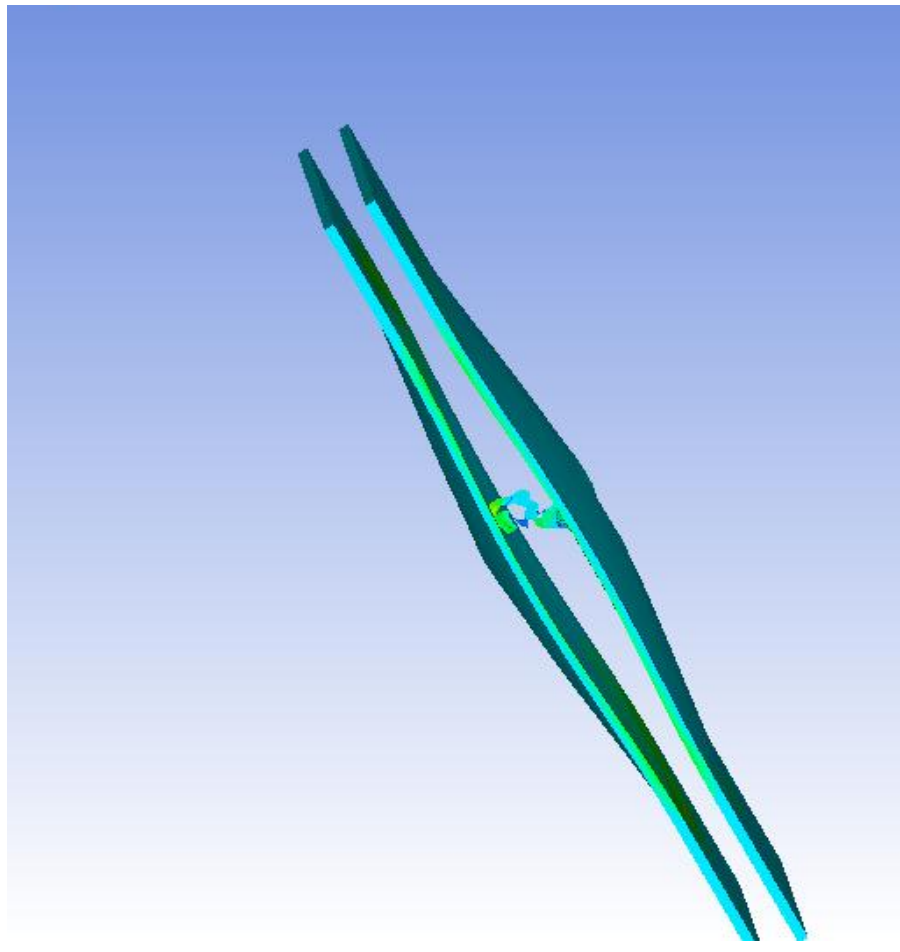

Fig. 6. Front jet initiates the explosive sandwich

\section{B. Full head system}

It consists of the front and rear warheads taking into account the weight of the engine and other parts of this projectile which are reduced to a tungsten block at the rear of the projectile. The results for those taken from the model (III-A) showed the effect of the front warhead on the rear warhead that begins to damage or deform before exploding on time. The progress of the solution showed problems in time due to the small value of the step calculations, to avoid this delay in time we used scaling model (III-B). A dome shield of steel 4340 was used to protect rear warhead from explosive wave of front charge, this shield success to protect rear charge and it head not being affected.

In model (III-B) problem of the step time of calculations is very small, this caused by Lagrange cells forming the outer shell of the projectile and which destroy with time, this destruction reduces the area of the cells, since the step time of calculations is calculated from the area of the smallest cell divided by the largest diameter of the cell and then divides the output by the local speed of sound.

To solve this dilemma, the number of cells has been reduced and their dimensions increased and eliminate the destroyed parts. This method has succeeded in solving the time step problem. After that simulation continued on the model, but as the model grew, the simulation reached to point where it could not avoid the very smallness of the time step calculation resulting to destruction of the casing in which Lagrange was used, so to continue in simulation we Lagrange cells by the technique of Reshaping Model (Remap). 


\section{Reshaping Model (Remap)}

The front and rear jetting in the two-dimensional Euler model was Remapping as follows: Front jetting remapped after penetrate target at $114.4 \mu \mathrm{s}$. The rear charge jetting was remapped at $60 \mu \mathrm{s}$ from the beginning of ignition. From remapping front and rear charge in A \& B the delay time is $(114.460=54.4 \mu \mathrm{s})$. The two-jetting front and rear succeeded to penetrate $350 \mathrm{~mm}$ Explosive Reactive Armor ERA when simulation was finished (Fig.7 illustrate the process).

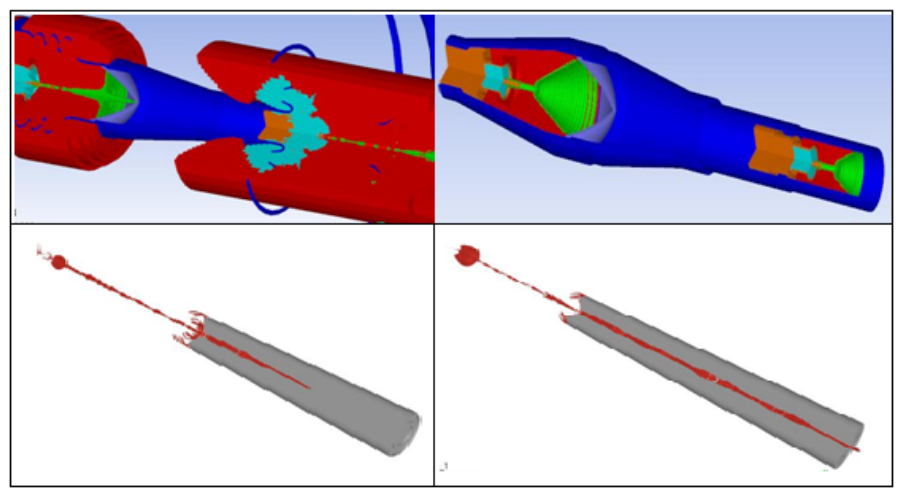

Fig. 7. The process of jet penetration

\section{CONCLUSIONS}

In this research PG-7 (40mm) anti tank hollow charge has been developed to tandem charge by adding precursor charge to defeat ERA. The effect of precursor charge on rear one was study a simulated as well as delayed ignition time between tow charges and total penetration agents steel target. The delayed time is $54.4 \mu$ s while penetration is $350 \mathrm{~mm}$.

\section{ACKNOWLEDGEMENTS}

The authors of this article acknowledge the Military Defense System Sudan MASAD for financial and technical support.

\section{REFERENCES}

[1] A. Zain and E. Musa, "Optimization of shaped charge parameters for oil well perforation:eur," Acad, vol. 2018, no. 4.

[2] A. Zain and E. Musa, "Simulation of $85 \mathrm{~mm}$ shaped charge jet tip velocity and penetration:int," J. Eng. Sci. Paradig, vol. 2017, no. 44.

[3] K. Goad and D. Halsey, Ammunition Including Grenades and Mines. Brasseys Publishers Ltd.

[4] J. Carleone, "Tactical missile warheads. progress in astronautics and aeronautics."

[5] M. Cook, The Science of High Explosives. Florida: Robert E. Krieger Publishing Company.

[6] F. Gunnery, "Field manual 6-40." 